\title{
The Effect of Cyclo-Alkane Additives in Waste Cooking Oil B20 Fuel on a Single Cylinder DI Diesel Engine
}

\author{
George Varghese, P. Mohanan, and Nithesh Naik
}

\begin{abstract}
Diesel engine combustion generates large amounts of oxides of nitrogen due to the presence of oxygen and nitrogen in the combustion chambers at high flame-temperatures. The main component of total cost of producing bio-diesel comprises the cost of raw materials. The use of a low cost feedstock such as waste cooking oil (WCO) will help make biodiesel much cheaper than diesel derived from petroleum sources. Waste cooking oil, which is otherwise wasted, is one of the most economical choices to extract biodiesel.

In this investigation, cyclo-pentane and cyclo-hexane were used as additives. The scope of this work also includes studies on various fuel-blends of $\mathrm{B} 20$ with varying percentages of additives and comparisons to fossil-based diesel. The studies performed also include investigations on the emission characteristics of $\mathbf{B 2 0}$ with additives at different loading conditions.

The tests performed indicate that the use of $B 20$ with $1.5 \%$ cyclo-hexane as an additive, resulted in a significant reduction in NOx emissions by $4 \%$ when compared to fossil diesel, at a normal injection timing of $27.5^{\circ}$ before-top dead-center (BTDC), at full-load conditions. It was also observed that the $\mathrm{B20}$ blend with $1 \%$ cyclo-pentane possessed the lowest smoke opacity of/by $36 \%$ at full-load conditions.
\end{abstract}

Index Terms-Biodiesel, cyclo-alkane, emission, performance, additives.

$\begin{array}{ll} & \text { NomenClatURE } \\ \text { CV } & \text { Calorific Value } \\ \text { IT (Inj. tim.) } & \text { Injection timing } \\ \text { BTDC } & \text { Before top dead center } \\ \text { Deg. } & \text { degree } \\ \text { B20CPEN1 } & \text { B20 + 1\% Cyclo- Pentane } \\ \text { B20CPEN1.5 } & \text { B20 + 1.5\% Cyclo- Pentane } \\ \text { B20CHEX1 } & \text { B20 + 1\% Cyclo- Hexane } \\ \text { B20CHEX1.5 } & \text { B20 + 1.5\% Cyclo- Hexane }\end{array}$

\section{INTRODUCTION}

The world today, is witnessing an increased interest in the use of bio-diesel, and researchers are examining the possibility of using rapeseed oil, sunflower oil, coconut oil, peanut oil, soybean oil, honge (or karanja), Jatropha and sesame oil, and methyl esters [1]. Waste cooking oil, which is otherwise wasted, is one of the most economical choices to

Manuscript received December 15, 2013; revised April 10, 2014.

George Varghese and Naik Nithesh are with Manipal Institute of Technology, Manipal, PIN- 576104, India (e-mail: george.varghese@manipal.edu, nithesh.naik@manipal.edu).

P. Mohanan is with National Institute of Technology Karnataka, Surathkal, PIN- 575025, India (e-mail: profmohanan@gmail.com). produce biodiesel [2].

Diesel engines generally operate with high air-fuel ratio at full-loads, generating large amounts of $\mathrm{NO}_{\mathrm{X}}$ in presence of abundant oxygen and nitrogen in the combustion chambers at high flame-temperatures. Increased environmental concerns and tougher emission norms require the development of advanced engine technologies to reduce $\mathrm{NO}_{\mathrm{X}}$ and particulate matter (PM) emissions.

The scope and objectives of this study include:

1) Selection of cyclo- alkane as additives

2) Testing of fuel-properties of B20 blend produced using WCO, with the addition of various percentages of cyclo-pentane and cyclo-hexane.

3) Investigations of the engine emission characteristics using data acquisition software, exhaust-gas analyzer and smoke-meter at various loads and single injection timing.

Biodiesel can be prepared from WCO through the transesterification process. It is a process of transforming one form of ester into another ester. The reaction breaks the triglyceride vegetable oil molecule into three molecules of esters and one molecule of glycerin. The molecules of esters bond with alcohol to form three molecules of alkyl esters. When methanol is used as alcohol, the resulting alkyl esters after transesterification are called as methyl esters [3]. Further steps including distillation, remove the remaining water content and poorly water-soluble impurities such as unreacted feedstock, and mono and diglycerides [4]. It is found that the smoke density and BSFC are slightly higher for vegetable oil blends compared to diesel. Vegetable oil blends show performance characteristics similar to diesel. Therefore, vegetable oil blends can be used in compression ignition engines. The performance and emission parameters for different fuel-blends are found to be very close to that of diesel [5].

The bio-diesel prepared based on the transesterification process can be blended with fossil diesel to obtain B20 blend [6]. It was reported that the calorific value of bio-diesel thus made, is lower than that of fossil diesel, and hence, the BSFC is greater by about $12 \%$. Since bio-diesel contains $11 \%$ oxygen, it has a lower heating-value than fossil diesel [7]. If $100 \%$ biodiesel is used, then it is required to burn 5-6\% more fuel volumetrically, in order to maintain the same level of power and performance in an engine [8]. It was also reported that the use of biodiesel in a conventional diesel engine results in substantial reduction in un-burnt hydrocarbon (UBHC), carbon monoxide $(\mathrm{CO})$, particulate matter $(\mathrm{PM})$ emission, and oxides of nitrogen $\left(\mathrm{NO}_{\mathrm{X}}\right)$ [9].

It is also found that the use of iso-butanol based diesel fuel-blends result in decreased $\mathrm{CO}$ and $\mathrm{NO}_{\mathrm{X}}$ emissions. 
However, the hydrocarbon (HC) emissions were found to increase with the use of blended diesel [7]. In the present study, blends of bio-diesel with fossil-based diesel were investigated for flash and ignition points, kinematic viscosity, greater-calorific-value and emission characteristics.

\section{MEthodology}

In this study, bio-diesel obtained by the trans-esterification of WCO, was blended volumetrically with petroleum-based diesel to get B20 diesel comprising $80 \%$ diesel and $20 \%$ bio-diesel. The fuel properties of the bio-diesel thus prepared were studied. The CV of the fuel-blend was found using the bomb-calorimeter. Subsequently, blend-components using various percentages of cyclo-hexane, and cyclo-pentane were prepared, and the fuel properties were tested. The fuel-properties recorded were then compared to those of fossil diesel.

The performance and emission tests were then conducted at the normal injection timing (inj. tim.) of $27.5^{\circ} \mathrm{BTDC}$, at a constant speed of $1500 \mathrm{rpm}$, a normal injection pressure of 180 bars and a compression-ratio of 17.5. The data was monitored and recorded on-line and was retrieved for further analysis. The experiments were conducted at no-load, 25\%, $50 \%, 75 \%$ and full-load conditions.

In a similar manner, fuel samples of petroleum-based diesel, B20 diesel blended with 1\% cyclo-pentane, (B20CPEN1), B20 diesel blended with 1.5\% cyclo-pentane (B20CPEN1.5), B20 diesel blended with 1\% cyclo-hexane (B20CHEX1), and B20 diesel blended with $1.5 \%$ cyclo-hexane (B20CHEX1.5) were tested.

Data such as fuel flow, exhaust temperature, brake thermal efficiency, BSFC, exhaust-smoke opacity, $\mathrm{NO}_{\mathrm{X}}, \mathrm{CO}, \mathrm{CO}_{2}$ and UBHC emissions were recorded at the above mentioned loading conditions. Steady state emission readings were taken for three trials, and the average of the recorded data was tabulated. Using this data, the emission characteristics of the diesel engine for different loads were compared and analyzed for various fuel samples.

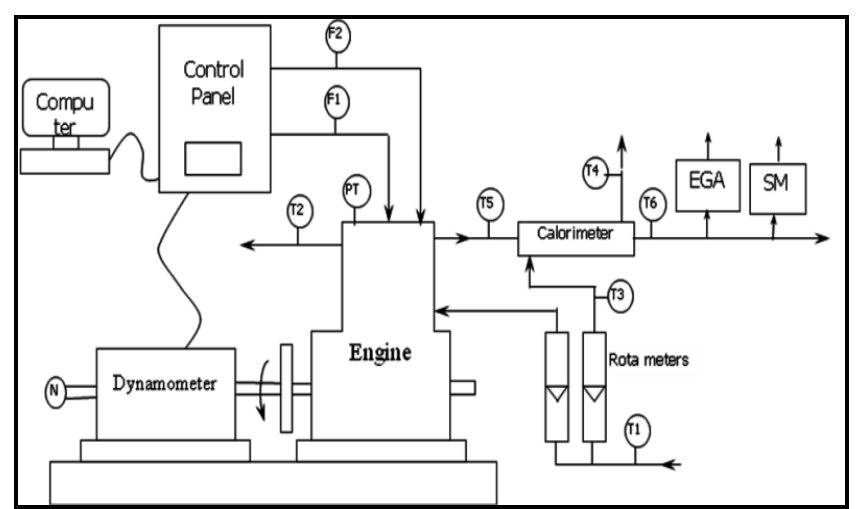

T1, T3: Inlet water temperature $\mathrm{T} 2$ : Outlet engine jacket water temperature T4: Outlet calorimeter water temperature T5: Exhaust gas temperature before calorimeter T6: Exhaust gas temperature after calorimeter F1: Fuel flow dp (differential pressure) unit F2: Air intake DP unit; PT: Pressure transducer W: Load; N: RPM Decoder; SM: Smoke meter EGA: Exhaust Gas Analyzer (5 gas)

Fig. 1. Schematic diagram of the experimental setup.
The schematic diagram of the complete experimental setup for the diesel engine test rig is shown in Fig. 1. The tests were conducted on a computerized single cylinder four-stroke, naturally aspirated, direct-injection, constant-speed and water-cooled diesel engine test rig. It was directly coupled to an eddy current dynamometer. The engine and the dynamometer were then interfaced to a control-panel connected to a computer.

\section{SELECTION OF CYClo AlKANES AS BLEND COMPONENTS}

The oil-industry specifies an aromatic content of up to $48 \%$ in petrol, in order to check harmful emissions. However, petrol manufactured has an aromatic content greater than 50\%, which is later moderated by using additional blend components. Diesel in contrast, has a lower aromatic content of $30 \%$ and an aliphatic content of $70 \%$ [6].

It was felt that aromatic compounds like benzene are used as blend-components to petrol in order to improve fuel properties like $\mathrm{CV}$, lubricity as well as the emission-characteristics. Similarly, it can be surmised that petroleum-based diesel fuels can be blended using aliphatic compounds with a chemical structure similar to that of benzene $\left(\mathrm{C}_{6} \mathrm{H}_{12}\right)$. This led to the choice of an aliphatic compound such as cyclo-alkanes that have ring structure. Cyclo- Pentane occurs as a colorless liquid with a petrol-like odor. It is the most stable of all the cyclo-alkanes. Cyclo-hexane is a colorless and volatile liquid with a slightly pungent odor.

The engine was run at $1500 \mathrm{rpm}$, and was tested for one injection timing, and five loading-conditions. Five trials were conducted for each fuel sample.

\section{RESULTS AND DISCUSSIONS}

Tests were performed for B20 blends with various percentages of cyclo-alkanes, for flash and ignition points, viscosity, and CV. The results are tabulated in Table I.

On comparing CV of B20CPEN1 to B20, it can be seen that the addition of $1 \%$ in volume of the blend-component cyclo-pentane $\left(\mathrm{C}_{5} \mathrm{H}_{10}\right)$ to $\mathrm{B} 20$, resulted in a minor increase in the $\mathrm{CV}$. This is associated with an increase in the kinematic viscosity $(v)$, and a significant reduction in the flash and ignition points.

Similarly, on comparing B20CPEN1.5 to B20, it can be seen that with the addition of $1.5 \%$ of $\mathrm{C}_{5} \mathrm{H}_{10}$, resulted in an increase in the $\mathrm{CV}$ by $4.29 \%$, coupled with a considerable decrease in the flash and ignition points. This indicates that the flash and ignition points are likely to reduce to ambient temperature conditions with further addition of $\mathrm{C}_{5} \mathrm{H}_{10}$. But since this trend can cause catastrophic accidents, it was decided to limit the $\mathrm{C}_{5} \mathrm{H}_{10}$ content to $1.5 \%$.

On the other hand, comparing B20CHEX1 to B20, the addition of $1 \%$ in volume of the blend-component cyclo-hexane (C6H12) to B20, resulted in a minor increase in the $\mathrm{CV}$, associated with an increase in the kinematic viscosity, and a significant reduction in the flash and ignition point's. Comparing B20CHEX1.5 to B20, it is seen that the addition of $1.5 \% \mathrm{C}_{6} \mathrm{H}_{12}$ increased the $\mathrm{CV}$ by $2.61 \%$. As the $\mathrm{CV}$ of the 
fuel is increased, the heat released during combustion also increases.

Considering the properties of B20CPEN1 and B20CPEN1.5, with respect to fossil-based diesel in Table I, it is observed that the flash point reduced by $3.57 \%$ and $14.29 \%$ respectively for the two blend-components. Similarly, considering the fuel properties of B20CHEX1 and B20CHEX1.5, with respect to fossil-based diesel, it is seen that the flash point increased by $3.45 \%$, and reduced by $3.57 \%$ respectively for the two blend-components.

It may be interesting to note that the ignition point of B20 is $24.14 \%$ higher than that of fossil-based diesel. The reduction in the flash and ignition points is mainly due to the volatility of the blend-components used. Since the flash and ignition point of B20CPEN1.5 was very low and almost close to that of room temperature, it was considered safe to limit the tests to only B20CHEX1, B20CHEX1.5, B20CPEN1 and B20CPEN1.5.

From the above discussions, it can be summarized that the use of cyclo-pentane (which is more volatile than cyclo-hexane), will aid in the reduction of flash and ignition points and this in turn will help reduce the peak pressure and temperature in the combustion chamber, resulting in a reduction in the $\mathrm{NO}_{\mathrm{X}}$ emissions.

It is felt that the reduction in the peak temperature will facilitate further research possibilities on investigations using higher compression ratios in a variable compression engine.

The data collected was analyzed and plotted in order to understand the behavior of various parameters with respect to change in load. The parameters such as the carbon monoxide, carbon dioxide, un-burnt hydrocarbons (UBHC), exhaust gas temperatures, $\mathrm{NO}_{\mathrm{X}}$ emissions and the smoke opacity were studied under varying loads.

\begin{tabular}{lcccc}
\multicolumn{5}{c}{ TABLE I: PROPERTIES OF VARIOUS BIODIESEL BLENDS } \\
\hline \hline Blends & CV kJ/kg & $\begin{array}{c}\text { Kinematic } \\
\text { Viscosity } \\
v(\mathrm{St})\end{array}$ & $\begin{array}{c}\text { Flash } \\
\text { Point } \\
\left({ }^{\circ} \mathrm{C}\right)\end{array}$ & $\begin{array}{c}\text { Ignition } \\
\text { Point } \\
\left({ }^{\circ} \mathrm{C}\right)\end{array}$ \\
\hline \hline Diesel & 43,068 & 0.03150 & 56 & 58 \\
\hline \hline B20 & 40,664 & 0.03200 & 68 & 72 \\
B20CPEN1 & 40,957 & 0.03366 & 54 & 62 \\
B20CPEN1.5 & 42,665 & 0.03155 & 48 & 56 \\
B20CHEX1 & 40,895 & 0.03255 & 58 & 61 \\
B20CHEX1. & 41,727 & 0.03366 & 54 & 58 \\
5 & & & & \\
\hline \hline
\end{tabular}

\section{A. Brake Thermal Efficiency}

It is seen that as the load increases Bth eff increases. At the normal IT of $27.5 \mathrm{deg}$. at loads greater than 50\%, B20CPEN1.5 and B20CHEX1.5 gives lesser Bth eff than fossil diesel. However B20CHEX1.5 gives the greatest Bth eff almost through the entire range of varying loads. The Bth eff of B20CPEN1 was lower at $50 \%$ load by $16 \%$ and at full load it was greater by $10 \%$ compared to fossil diesel. The Bth eff of B20CPEN1.5 was lower at $50 \%$ load by $7 \%$ and at full load it was greater by $12 \%$ compared to fossil diesel. At 27.5 BTDC. IT the Bth eff of B20CHEX1 was greater by $3.46 \%$ at half load and greater by $15.5 \%$ at full load compared to fossil diesel. At $27.5 \mathrm{deg}$. BTDC. IT the Bth eff of B20CHEX1.5 was $2.86 \%$ greater at half load and $3.2 \%$ greater at full load compared to fossil diesel. It is very clear that at lower loads the Bth eff of B20 fuels with $\mathrm{C}_{5} \mathrm{H}_{10}$ components is lesser compared to B20 fuels with $\mathrm{C}_{6} \mathrm{H}_{12}$ components. The variations in different blends were mainly due to increase in CV. However for the blend B20CHEX1.5 it was found to be lower which may be due to less amount of oxygen present after the increase in total number of carbon atoms.

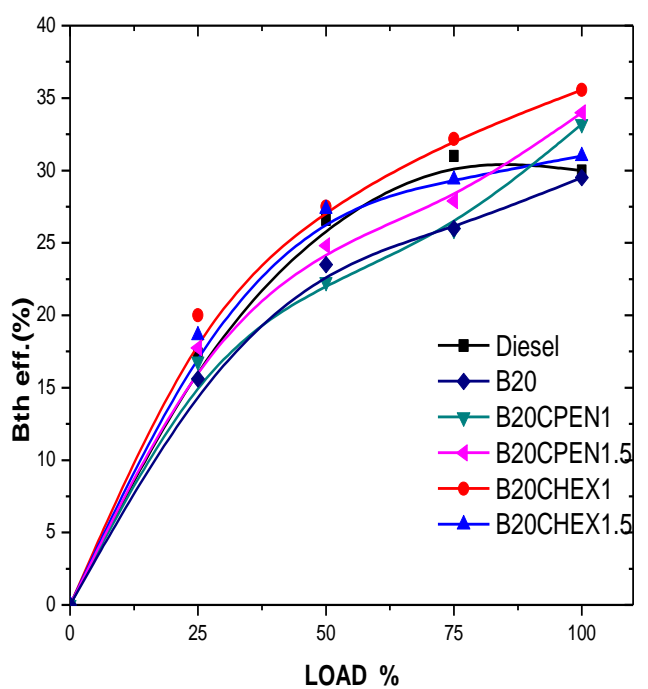

Fig. 2. Brake thermal efficiency of various blends for different loads at 27.5 deg. injection timing

\section{B. Brake Specific Fuel Consumption (BSFC)}

For lower loads, blends of biodiesel gives lower BSFC than fossil diesel. However at greater loads fossil diesel gives the least BSFC and all the B20 blends gives lower BSFC. This was due to the lower calorifc value of B20 blends compared to fossil diesel. At $27.5 \mathrm{deg}$. BTDC. IT the BSFC of blend B20CPEN1 was $5.7 \%$ greater at half load and $1.2 \%$ lower at full load compared to fossil diesel. The BSFC of B20CPEN1.5 was 3\% greater at half load and $2.75 \%$ lower at full load compared to fossil diesel.

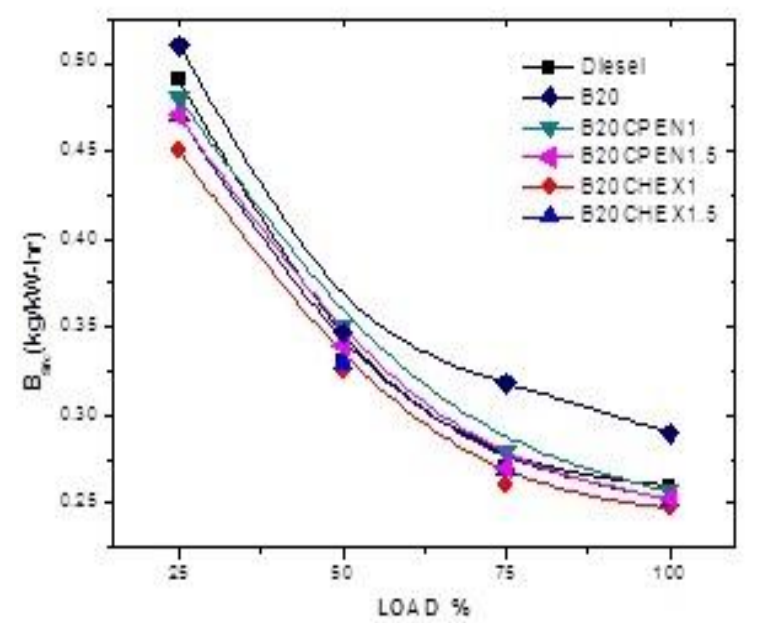

Fig. 3. BSFC of various blends for different Loads at $27.5 \mathrm{deg}$. Injection Timing

The BSFC of B20CHEX1 was lower by $1.4 \%$ at half load and by $5 \%$ at full load compared to fossil diesel. The BSFC of 
the blend B20CHEX1.5 was almost the same at half load and lower by $2.8 \%$ at full load when compared to fossil diesel.

\section{Carbon Monoxide (CO) Emissions}

The blend B20CPEN1.5 at $27.5 \mathrm{deg}$. BTDC. showed $16.6 \%$ greater $\mathrm{CO}$ emissions by at half load and was lower by $36.8 \%$ at full load compared to fossil diesel. For B20CHEX1 at 27.5 deg. BTDC. CO emissions were $33.33 \%$ greater at half load and lower by $16 \%$ at full load compared to fossil diesel. For B20CHEX1.5 at $27.5 \mathrm{deg}$. BTDC. CO emissions were greater by $16 \%$ at half load and lower by $13.16 \%$ at full load compared to fossil diesel. The blend component aided in reducing the $\mathrm{CO}$ emissions by lowering the flash and ignition points just enough to have the optimum combustion temperature and pressure. The decrease in $\mathrm{CO}$ emission of B20 blend was found to be $5.5 \%$ and $16.67 \%$ compared to the fossil diesel at half and full load respectively.

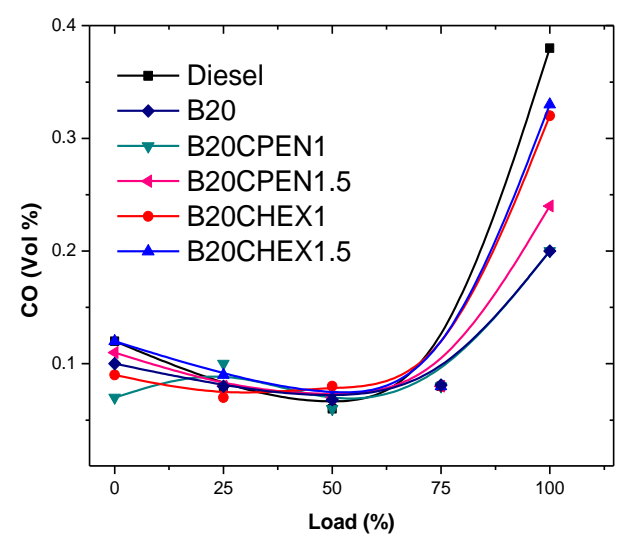

Fig. 4. CO Emissions of various blends at different loads at $27.5 \mathrm{deg}$. injection timing.

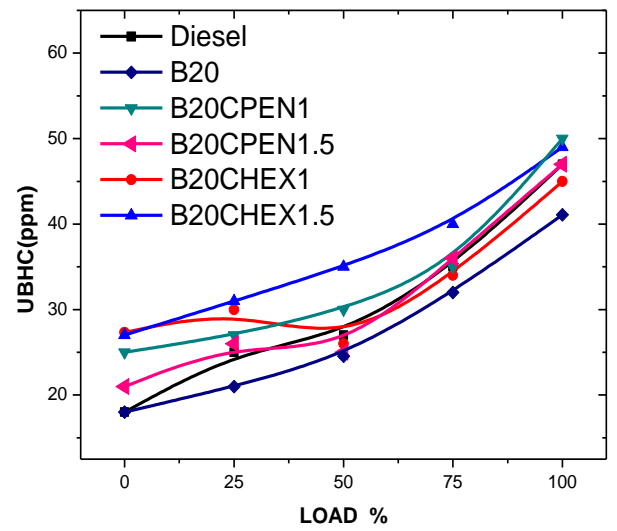

Fig. 5. UBHC Emissions of various Blends at different loads at $27.5 \mathrm{deg}$. BTDC. injection timing.

\section{Un-Burnt Hydrocarbon Emissions (UBHC)}

In Fig. 3. it is seen that at the normal IT of $27.5 \mathrm{deg}$ BTDC. set by the engine manufacturer, fossil diesel gives the least UBHC emissions and among the biodiesel blends the B20CPEN1.5 gives the least emissions at half and full load conditions. For B20CPEN1 UBHC emission increased by $10 \%$ at half load and by $6 \%$ at full load compared to fossil diesel. For B20CPEN1.5 the UBHC reduced by $7.4 \%$ at half load and there was no change in emission levels at full load compared to fossil diesel. At $27.5 \mathrm{deg}$. BTDC. IT for B20CHEX1 the UBHC reduced by $3.7 \%$ at half load and by $4.25 \%$ at full load. At $27.5 \mathrm{deg}$. BTDC. IT the UBHC for B20CHEX1.5 increased by $23 \%$ at half load and by $4 \%$ at full load compared to fossil diesel. The B20 blend gives $15.2 \%$ and $9.33 \%$ lower UBHC at $50 \%$ and $100 \%$ loads respectively compared to fossil diesel. By comparison the B20 blend gives least UBHC due to high peak pressures raising the peak temperature resulting in better combustion. and inclusion of blend components has increased the UBHC emission because of lower peak pressures.

\section{E. $N O_{X}$ Emissions}

From Fig. 4. showing the $\mathrm{NO}_{\mathrm{X}}$ emissions for various fuel blends at different loads and at normal IT of $27.5 \mathrm{deg}$. BTDC. it is seen that the biodiesel blend with $\mathrm{C} 5 \mathrm{H} 10$ blend component showed the greatest $\mathrm{NO}_{\mathrm{X}}$ emissions.

The blends with cyclo- hexane blend component gave lower $\mathrm{NO}_{\mathrm{X}}$ emissions than fossil diesel. The $\mathrm{NO}_{\mathrm{X}}$ emissions for B20CPEN1 increased by $6.1 \%$ at half load and by $4 \%$ at full load compared to fossil diesel. For B20CPEN1.5 the $\mathrm{NO}_{\mathrm{X}}$ emission increased by $4.6 \%$ at half load and by $3 \%$ at full load. The $\mathrm{NO}_{\mathrm{X}}$ emissions for B20CHEX1 increased by $11 \%$ at half load and was almost the same at full load. For B20CHEX1.5 at $27.5 \mathrm{deg}$. the $\mathrm{NO}_{\mathrm{X}}$ emissions increased by $15 \%$ at half load and reduced by $3 \%$ at full load compared to fossil diesel. B20 blend gives $22.18 \%$ and $11.26 \%$ greater $\mathrm{NO}_{\mathrm{X}}$ at $50 \%$ and $100 \%$ load compared to fossil diesel.

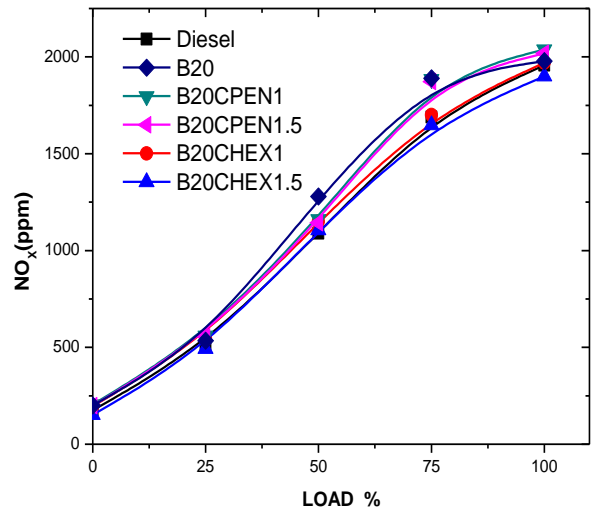

Fig. 6. $\mathrm{NO}_{\mathrm{X}}$ Emission of various blends for different loads at $27.5 \mathrm{deg}$. BTDC. injection timing.

This is because B20 gives the greatest peak pressures during combustion. With blend component, $\mathrm{NO}_{\mathrm{X}}$ emissions were reduced significantly for B20 compared to fossil diesel.

\section{CONCLUSIONS}

The following conclusions have been obtained:

B20CHEX1 gave the highest Bth Eff for all loads among all the blends with additives.

B20CHEX1 gave the least BSFC for all loads among all the blends with additives.

B20CPEN1 gave the lowest CO emission among all the blends with additives.

B20CHEX1 gave the lowest UBHC emissions among all the blends with additives.

B20CHEX1.5 gave the lowest $\mathrm{NO}_{\mathrm{X}}$ emissions among all the blends with additives.

Use of additives has helped us reduce the $\mathrm{NO}_{\mathrm{X}}$ emissions compared to B20 and fossil diesel, but the $\mathrm{CO}$ and UBHC emissions are still higher than B20 blend and fossil diesel.

Cyclo- Hexane blend component was found to be the least 
expensive for producing blend.

\section{REFERENCES}

[1] H. J. Prakash "Performance and emission analysis of a CI engine fuelled with WCO biodiesel with EGR technique and DEE as blend component," National Institute of Technology Karnataka, Surathkal, M.Tech Thesis, pp. 1-8, 2010.

[2] X. Menga, G. Chena, and Y. Wang, "Biodiesel production from waste cooking oil via alkali catalyst and its engine test," Fuel Processing Technology, vol. 89, no. 9, pp. 851- 857, 2008.

[3] R. Lawrence. (2010). Richard Making a Diesel Fuel Alternative from Vegetable Oil. [Online]. Available: http://www.reliance.org.

[4] A. Steinbach, "A Comprehensive Analysis of Bio-Diesel," Bio-Diesel Magazine, November 2007, pp. 1-12.

[5] Y. Yuan, D. Mei, and Z. Yang, "Combustion and emissions of the diesel engines using biodiesel fuel," J. Frontiers in Mechanical Engineering, vol. 3, no. 2, pp. 189-192, 2008.

[6] S. Shailendra, "Biodiesel development from rice bran oil: trans-esterification process optimization and fuel characterization," Energy Conversion and Management, vol. 49, pp. 1248-1257, 2008.

[7] R. M. Davis, Biodiesel and vegetable oil as a fuel Martin Davies Nuffield Farming Scholarship Trust, 2007.

[8] N. R. Banapurmath, P. G. Tewari, and R. S. Hosmath, "Experimental investigations of a four stroke single cylinder direct injection diesel engine operated on dual fuel mode with producer gas as inducted fue and Honge oil and its methyl ester (HOME) 8s injected fuels," Renewable Energy, vol. 33, pp. 2007- 2018, 2007.

[9] A. Murugesan, "Biodiesel as an alternative fuel for diesel engines - A review," Renewable and Sustainable Energy Reviews, vol. 13, pp. 653-662, 2009.

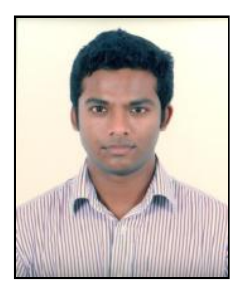

George Varghese is an assistant professor at the Department of Mechanical and Manufacturing Engineering, Manipal Institute of Technology, Manipal.

$\mathrm{He}$ has been working at Manipal Institute of technology, Manipal since two years ago as an assistant professor. He completed his master's degree from National Institute of Technology Karnataka, Surathkal. He has published many international and national papers at conferences. He has guided many projects in the field of biodiesel fuels.

Mr. George Varghese is a lifetime member of the Combustion Institute-Indian Section. 
